\title{
Segmented Poly(urethane-urea)s Synthesized Directly from Isocyanate-Terminated Prepolymers and Masked Diamines I. Quantitative Synthesis
}

\author{
Emiko Yamazaki, Hiroyuki Hanahata, ${ }^{\dagger}$ Jun-ichi Hiwatari, \\ and Yoshiharu Kitahama ${ }^{\dagger \dagger}$ \\ Central Laboratory (Takatsuki), Asahi Chemical Industry Co., Ltd., \\ 11-7 Hacchonawate-cho, Takatsuki, Osaka 569, Japan
}

(Received January 29, 1997)

\begin{abstract}
An attempt was made for quantitative synthesis of segmented poly(urethane-urea)s (PUUs), not via solution state, but directly from an isocyanate-terminated prepolymer prepared from an excess molar concentration of 4,4'-methylenediphenyldiisocyanate with poly(tetramethyleneoxide) $\left(\bar{M}_{n}=2010\right)$ and reaction products from acetone and ethylenediamine (EDA) consisting of $N$-isopropylideneethylenediamine (1), $N, N^{\prime}$-diisopropylideneethylenediamine (2), 2,2-dimethylimidazolidine (3) as main product, water, and the unreacted raw materials. With increasing the masking ratio of acetone to EDA, the concentrations of the ketimine groups and water increase while those of the imidazolidine and EDA generally decrease, the molar fraction of the by-product from the reaction of an isocyanate group with water was increased mainly because of the catalytic effect of the ketimine groups. Acetic acid played the significant roll to eliminate the side reaction by accelerating disappearance rate of (1) ((2)) and the quantitative yield of PUU was attained at $40^{\circ} \mathrm{C}$ when the acid concentration and the masking ratio were $3.50 \times 10^{-3} \mathrm{~mol} \mathrm{~kg}^{-1}$ and 1.4 , respectively.

KEY WORDS Poly(urethane-urea)s / Bulk Polymerization / Quantitative Yield / Isocyanate-Terminated Prepolymer / Masked Diamines / Water / Acid /
\end{abstract}

Segmented poly(urethane-urea)s (PUUs) compose of a class of elastomers exhibiting superior extensibility, toughness and durability over segmented poly(urethane)s and are extensively used in the fields from textile fibers to medical prosthesis. ${ }^{1,2}$ They are usually synthesized in a two-step process ${ }^{3}$; (1) An excess molar concentration of a diisocyanate reacted with a polyether or a polyester diol (number-average molecular weight is in range $1000-3000)$ to form an isocyanate-terminated prepolymer (ITPP) in bulk or in the solvent like $N, N$ dimethylacetamide (DMAc) or $N, N$-dimethylformamide (Scheme 1). (2) The prepolymer is then polymerized to form a PUU with an aliphatic diamine such as ethylenediamine (EDA) or propylenediamine (PDA) in the same solvent.

The roll of the solvent is to avoid the abrupt polymerization reaction due to a diffusion-controlled reaction rate between the isocyanate (NCO) group and the amino group ${ }^{4}$ forming a urea group (Urea I). If the polymerization reaction rate is significantly reduced by any methods, the bulk polymerization reaction without any solvents becomes practical, affording a convenient and economical route from the industrial view points.

Variety of methods have been reported ${ }^{5,6}$ for controlling the apparent $\mathrm{NCO}$-amine reaction rate with the use of so called a 'masked' diisocyanate or a diamine, capable of undergoing a reformation reaction of the groups ('demasking reaction') in the polymerization reactions. Phenol, cresol, and ethyl acetoacetate are of industrial importance for masking $\mathrm{NCO}$ groups. Various ketones such as ethyl methyl ketone and dipropyl ketone are also commercially used for masking diamines. ${ }^{7,8}$ However, as far as the authors know, no methods have attained the goal to satisfy significant reduction of polymerization rates as well as quantitative yield of the Urea I so far.

On the other hand, quite recently, we have successfully identified the reaction products from acetone and EDA (masked EDA), ${ }^{9}$ as being a mixture of $N$-isopropylideneethylenediamine, 2,2-dimethylimidazolidine, $N, N^{\prime}$-diisopropylideneethylenediamine, water, and the raw materials in an equilibrium state and we became aware of the possibility that the reaction products were capable of forming Urea I when the products were mixed with phenylisocyanate as a model compound of ITPP. At the same time it was found that the reaction of an NCO with water inevitably took place to form the by-product

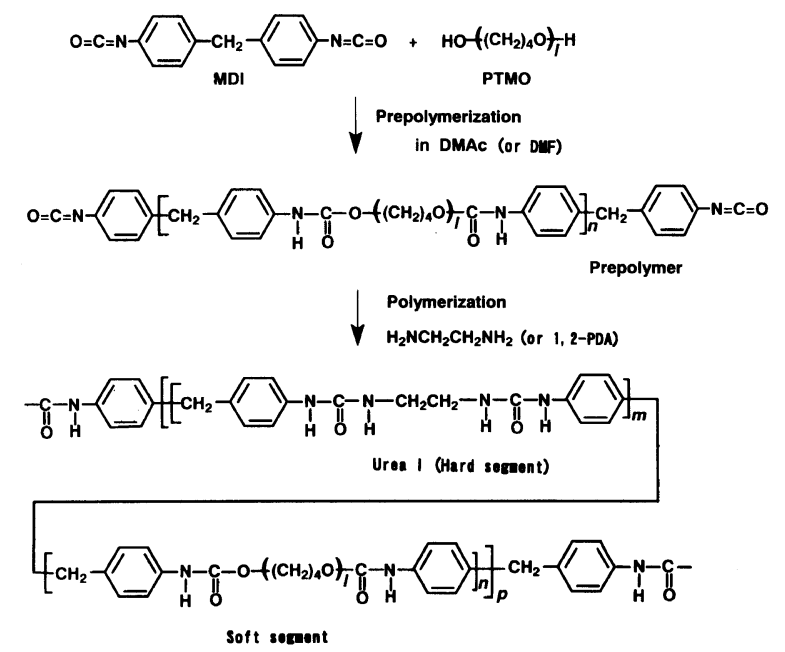

Scheme 1. Typical synthetic route for segmented poly(urethane-urea) (PUU).

\footnotetext{
† To whom correspondence should be addressed.

${ }^{\dagger t}$ Present address: Japan Elastomer Co., Ltd., Oaza Nakanosu 2, Oita 870-01, Japan.
} 
(1,3-diphenylurea), contaminating the main product. To our surprise, however, when the masked EDA was prepared in the presence of water and used for reactions with the NCO, the Urea I yield increased.

Utilizing the above results of the model reactions, a more systematic study was done in this paper by using ITPP prepared from an excess molar concentration of 4,4'-methylenediphenyldiisocyanate (MDI) and poly(tetramethyleneoxide) (PTMO, $\bar{M}_{n}=2010$ ) and the masked EDA in view of elimination of an analogous by-product. An emphasis was laid on the effects of the composition of masked EDA and the acid concentration which is expected to play a more effective roll over water.

\section{EXPERIMENTAL}

\section{Materials}

Reagent-grade $(99.5 \%)$ acetone and ethylenediamine (EDA) supplied by Wako Pure Chemical Industries, Ltd. (Kyoto, Japan) were distilled before use. Deuterated acetone $(99.95 \%)$ purchased also from the same manufacturer was used as received. Fiber-grade 4,4'-methylenediphenyldiisocyanate (MDI) manufactured by Nippon Polyurethane Industry Co., Ltd. (Tokyo, Japan) was freshly distilled at $185^{\circ} \mathrm{C} / 300 \mathrm{~Pa}$. The purity of MDI was higher than $99.9 \%$ as determined by the conventional titration method. ${ }^{10}$ Poly(tetramethyleneoxide) (PTMO) manufactured by Asahi Chemical Industry Co., Ltd. (Tokyo, Japan) was dehydrated at $90^{\circ} \mathrm{C} / 400 \mathrm{~Pa}$. The water content was $15 \mathrm{ppm}$ as measured by a moisture meter, Model CA-2 manufactured by Mitsubishi Chemical Industry Co. Ltd. (Tokyo, Japan). The number-average molecular weight of PTMO $\left(\bar{M}_{n}\right)$ was determined by the end-group analysis. ${ }^{11}$

\section{Preparation of Reaction Products (AE) from Acetone and EDA}

The preparation procedure for the reaction products (sample code AE1-7) from acetone and EDA is typically described for AE1. Eighty grams of acetone $(1.377 \mathrm{~mol})$ and $82.76 \mathrm{~g}$ of EDA $(1.377 \mathrm{~mol})$ were put directly into a $0.5 \mathrm{~L}$ round-bottomed flask with a detachable three-neck top in a dry box. The reaction mixture was stirred under the nitrogen atmosphere for $80 \mathrm{~min}$ at $40^{\circ} \mathrm{C}$. The composition of the AE1 sample was determined as follows; a reaction mixture whose masking ratio was exactly the same as that of AE1 but contained deuterated acetone ([acetone $] /\left[\right.$ acetone $\left.-d_{6}\right]=5 / 1, \mathrm{~mol} / \mathrm{mol}$ ) as a solvent for locking was directly put into a NMR sample tube (5$\mathrm{mm} \phi$ ) and subjected to ${ }^{13} \mathrm{C}$ NMR measurement after the reaction for $80 \mathrm{~min}$ at $40^{\circ} \mathrm{C}$. The preparation procedures and the determination of the compositions of other AE samples were followed by those for the AE1. All the reaction conditions as well as the composition of the AE samples prepared in this paper are listed in Table I. For the preparation of AE6 and 7 the certain amount of water (also Table I) was added to the AE2 and 4, respectively and the mixture stood for reaction for another $80 \mathrm{~min}$ at $40^{\circ} \mathrm{C}$.

\section{Synthesis of ITPP from Reaction of MDI with PTMO in Bulk}

One hundred grams of MDI $(0.400 \mathrm{~mol})$ and $434.1 \mathrm{~g}$ of PTMO $(0.216 \mathrm{~mol})$ were put directly into a $1 \mathrm{~L}$ roundbottomed flask with a four-neck top in a dry box. The reaction mixture was stirred at $70^{\circ} \mathrm{C}$ for $3 \mathrm{~h}$ under the nitrogen atmosphere. After this prepolymerization reaction, the small amount of the prepolymer (ITPP) taken out from the flask was subjected to determination of NCO concentration by the titration method previously described. The concentration of NCO groups was $0.679 \mathrm{~mol} \mathrm{~kg}^{-1}$. After the determination of the NCO concentration, the ITPP was immediately used to avoid the side reactions mainly between the ITPP. ${ }^{12}$

\section{Direct Syntheses of PUUS (DSPUU Reaction) by Mixing ITPP and AE Samples}

A series of the DSPUU reactions (DSPUU1-11) were carried out by mixing AE and ITPP samples vigorously at $40^{\circ} \mathrm{C}$ for average mixing time of $5 \mathrm{~s}$ using the mixing device with 13 elements (Scheme 2) manufactured by Noritake Co., Ltd. (Nagoya, Japan). The two pistons (b in the scheme) are pushed into the cylinders, $\mathrm{c}$ by moving the lever, e repeatedly. The mixture was then cast on a glass plate under $\mathrm{N}_{2}$ atmosphere to obtain thin films (thickness of $c a .100 \mu \mathrm{m}$ ). The reaction temperature was chosen as $40^{\circ} \mathrm{C}$. After the reaction was conducted for $400 \mathrm{~s}$, the DSPUU samples were dried under vacuum $(300 \mathrm{~Pa})$ for $5 \mathrm{~h}$. The reaction conditions for all the DSPUU reactions are summarized in Table II.

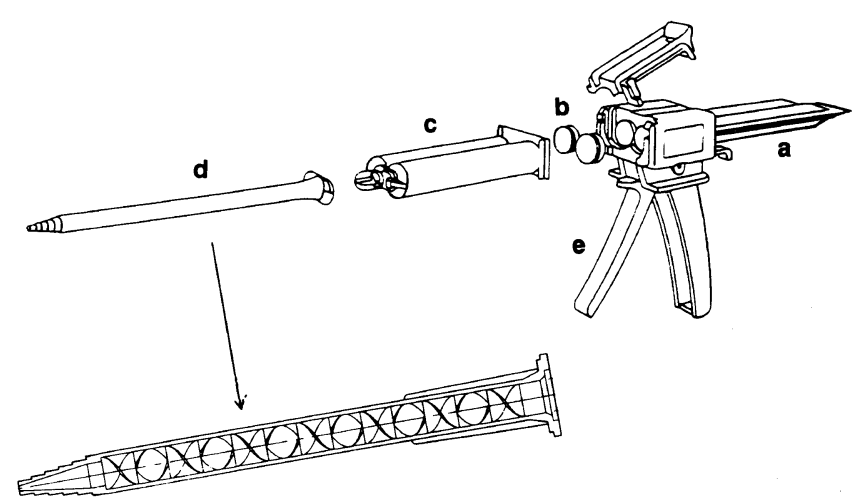

Scheme 2. Mixing device for direct synthesis of PUU; a, plunger; $b$, pistons; c, two separated cylinders; d, mixer with 13 elements; e, lever.

\section{MEASUREMENTS AND ANALYSES}

${ }^{13} \mathrm{C}$ NMR spectra were recorded on a Pulse Fourier transform spectrometer (JEOL Model GSX-400) operating at $100.54 \mathrm{MHz}$. In all NMR experiments the chemical shifts were recorded in part per million (ppm) from tetramethylsilane as internal standard. ${ }^{13} \mathrm{C}$ NMR measurements of DSPUU samples were carried out at $80^{\circ} \mathrm{C}$ in the mixture of DMAc and dimethylsulfoxide- $d_{6}$ (ca. $5: 1, \mathrm{v} / \mathrm{v}$ ) under the following conditions: complete decoupling mode; delay time $30 \mathrm{~s}$; acquisition time $0.655 \mathrm{~s}$; pulse width $5.5 \mu \mathrm{s}\left(45^{\circ}\right.$ pulse $)$; accumulation times more than 3000 times.

The weight-average molecular weight $\left(\bar{M}_{w}\right)$ of a DSPUU sample was calculated based on eq $1^{13}$;

$$
\bar{M}_{w}=\exp \{(\ln [\eta]+2.293) / 0.59\}
$$

where the limiting viscosity number $([\eta])$ of DSPUU samples was measured in a Ubbelohde viscometer at 
Table I. Preparation conditions and composition of AE samples

\begin{tabular}{|c|c|c|c|c|c|c|c|c|c|c|c|}
\hline \multirow{2}{*}{$\begin{array}{c}\text { Sample } \\
\text { code }\end{array}$} & \multirow{2}{*}{\multicolumn{2}{|c|}{$[\text { Acetone }]_{0} /[\mathrm{EDA}]_{0}\left[\mathrm{H}_{2} \mathrm{O}\right]_{0} /[\mathrm{EDA}]_{0}$}} & \multicolumn{5}{|c|}{ AE composition } & \multicolumn{4}{|c|}{ Composition of functional groups } \\
\hline & & & EDA & (1) & (2) & (3) & $\frac{\mathrm{H}_{2} \mathrm{O}}{\mathrm{mol} \% \mathrm{~b}}$ & {$\left[\mathrm{NH}_{2}\right]$} & {$[\mathrm{NH}]$} & [Ketimine] & $\frac{\mathrm{H}_{2} \mathrm{O}}{\mathrm{mol}^{\circ}{ }^{\mathrm{b}}}$ \\
\hline $\mathrm{AE} 1$ & 1.0 & - & 16.1 & 15.9 & 2.7 & 65.3 & 43.3 & 24.1 & 65.3 & 10.6 & 43.3 \\
\hline AE2 & 1.4 & - & 3.6 & 17.7 & 14.9 & 63.8 & 55.7 & 12.5 & 63.8 & 23.7 & 55.7 \\
\hline AE4 & 2.5 & - & 1.3 & 18.6 & 29.8 & 50.3 & 64.3 & 10.6 & 50.3 & 39.1 & 64.3 \\
\hline AE5 & 3.0 & - & 0.7 & 15.2 & 39.6 & 44.5 & 69.5 & 8.3 & 44.5 & 47.2 & 69.5 \\
\hline AE6 & 1.4 & $0.5^{\mathrm{c}}$ & 4.6 & 18.0 & 12.1 & 65.3 & 78.8 & 13.6 & 65.3 & 21.1 & 78.8 \\
\hline AE7 & 2.5 & $0.5^{\mathrm{d}}$ & 2.3 & 18.2 & 17.7 & 61.8 & 82.7 & 11.4 & 61.8 & 26.8 & 82.7 \\
\hline
\end{tabular}

${ }^{a}$ The compounds such as (1), (2), and (3) are $N$-isopropylideneethylenediamine, $N, N^{\prime}$-diisopropylideneethylenediamine, and 2,2-dimethylimidazolidine, respectively. The AE composition was calculated based on EDA used. ${ }^{\mathrm{b}}$ Calculated based on the formula:10 $\left.{ }^{2}\left[\mathrm{H}_{2} \mathrm{O}\right] /\left\{2[\mathrm{EDA}]_{0}\right]\right\}=$ $10^{2}([(1)]+2[(2)]+[(3)]) /\left\{2[\mathrm{EDA}]_{0}\right\}$. In the case of AE6 and 7 , the molar fraction is given by $10^{2}\left\{\left[\mathrm{H}_{2} \mathrm{O}\right]+\left[\mathrm{H}_{2} \mathrm{O}\right]_{0}\right\} /\left\{2[\mathrm{EDA}]_{0}\right\}$. $\mathrm{c}, \mathrm{d}$ The initial concentration of water added to AE2 and 4 samples, respectively.

$25 \pm 0.05^{\circ} \mathrm{C}$.

The yield defined as that for Urea I was calculated by ${ }^{13} \mathrm{C}$ NMR measurement based on eq 2;

$$
Y_{\text {Urea I }}=10^{2} I_{\text {Ureal }} /\left\{I_{\text {uret }}\left([\mathrm{MDI}]_{0} /[\text { PTMO }]_{0}-1\right)\right\}
$$

where $[\mathrm{MDI}]_{0} /[\mathrm{PTMO}]_{0}, I_{\text {Ureal }}$, and $I_{\text {uret }}$ represent the initial concentration ratio of MDI and PTMO, the peak intensity of Urea I carbonyl at $154.2 \mathrm{ppm}$ and that of urethane carbonyl at $156.1 \mathrm{ppm},{ }^{14}$ respectively.

\section{RESULTS AND DISCUSSION}

\section{Composition of AE Samples}

Table I lists the composition of each AE sample. With increasing the initial concentration ratio of acetone to EDA, the concentrations of EDA and the main product, 2,2-dimethylimidazolidine, (3) decreased, accompanying with the gradual increase in the concentration of $N, N^{\prime}-$ diisopropylideneethylenediamine, (2) and water. There was little tendency for $\mathrm{N}$-isopropylideneethylenediamine, (1). The concentration of EDA was abruptly decreased when the ratio changed from 1.0 to 1.4 . With respect to the functional groups such as an amino group $\left(\mathrm{NH}_{2}\right)$ of EDA and (1), an imino group (NH) of (3), and a ketimine group of (1) and (2), there is more clear tendency that the concentrations of the $\mathrm{NH}_{2}$ and $\mathrm{NH}$ groups decrease, on the contrary the concentration of the ketimine groups increased with increasing the ratio.

The effect of addition of water $(50 \mathrm{~mol} \%$ of water for the initial concentration of EDA) on the composition of AE2 and 4 samples for preparing AE6 and 7, respectively was also listed in Table I. There observed the common tendency for the two cases that the concentration of (2) decreased and that of (3) increased by adding water (in terms of the concentrations of the functional groups, the concentration of the $\mathrm{NH}_{2}$ groups increased slightly, however, the increase in the concentration of the $\mathrm{NH}$ groups and the decrease in that of the ketimine groups were significant).

\section{DSPUU Reactions in the Absence of Acetic Acid}

Effect of AE Composition on PUU Yield. Seven DSPUU reactions (DSPUU1-7) were performed using $\mathrm{AE} 1-7$ in order to know dependence of the $\mathrm{AE}$ composition on a PUU yield, determined by the ${ }^{13} \mathrm{C}$ NMR
Table II. DSPUU reaction conditions for DSPUU1-11

\begin{tabular}{|c|c|c|c|c|}
\hline \multirow{2}{*}{$\begin{array}{l}\text { Sample } \\
\text { code }\end{array}$} & \multirow{2}{*}{$\begin{array}{c}\mathrm{AE} \\
\text { sample } \\
\text { code }\end{array}$} & \multirow{2}{*}{$\frac{[\mathrm{ITPP}] /[\mathrm{AE}]^{\mathrm{a}}}{\mathrm{mol} \mathrm{mol}^{-1}}$} & \multirow{2}{*}{$\frac{\begin{array}{c}{\left[\mathrm{CH}_{3} \mathrm{COOH}\right]} \\
\times 10^{-3}\end{array}}{\mathrm{~mol} \mathrm{~kg}^{-1}}$} & \multirow{2}{*}{$\frac{\begin{array}{c}\text { Yields of } \\
\text { Urea I/Urea II }\end{array}}{\text { mol\% }}$} \\
\hline & & & & \\
\hline DSPUU1 & 1 & 1.0 & - & - \\
\hline DSPUU2 & 2 & 1.0 & - & $72 / 28$ \\
\hline DSPUU3 & 3 & 1.0 & - & $64 / 36$ \\
\hline DSPUU4 & 4 & 1.0 & - & $58 / 42$ \\
\hline DSPUU5 & 5 & 1.0 & - & $50 / 50$ \\
\hline DSPUU6 & 6 & 1.0 & - & $64 / 36$ \\
\hline DSPUU7 & 7 & 1.0 & - & $64 / 36$ \\
\hline DSPUU8 & 7 & 1.0 & 0.70 & $84 / 16$ \\
\hline DSPUU9 & 7 & 1.0 & 1.05 & $88 / 12$ \\
\hline DSPUU10 & 7 & 1.0 & 1.75 & $96 / 4$ \\
\hline DSPUU11 & 7 & 1.0 & 3.50 & $100 / 0$ \\
\hline
\end{tabular}

${ }^{a}$ Calculated based on the concentration of NCO groups of ITPP and the initial concentration of the amino groups of EDA used for the preparation of the AE samples.

measurement. The reaction conditions are compiled in Table II. In the case of DSPUU1 reaction where the masking ratio of acetone to EDA, [acetone $]_{0} /[\mathrm{EDA}]_{0}$ of AE1 was 1.0, homogeneous mixing of ITPP and AE1 was impossible due to the abrupt increase in the mixture viscosity caused by almost the instantaneous polymerization reaction with the unreacted EDA. ${ }^{15}$ When the masking ratio increased to 1.4 (DSPUU2 reaction) or more the reactions proceeded dramatically mildly and the mixtures remained as fluid at least during mixing.

Figure 1 shows the ${ }^{13} \mathrm{C}$ NMR spectrum of DSPUU2 as a representative. The peaks of the Urea I carbonyl and the urethane carbonyl (Scheme 1) were observed at 154.2 and $156.1 \mathrm{ppm}$, respectively. ${ }^{14}$ The assignment of other signals relating to Urea I aromatic carbons was also followed by the same literature and indicated in the figure. The several signals of a by-product were assigned to be those of the product formed from the reaction of an NCO with water (Urea II). This signal assignment was made by referring the results on the polymer prepared from ITPP and water. ${ }^{16}$ The assignment results of Urea II are also shown in this figure. Similar spectra were obtained for DSPUU3 - 6 expect for the intensity difference of each signal as observed in Figure 1.

Figure 2 shows the plots of the molar fractions of functional groups in the AE samples, [acetone $]_{0} /[\mathrm{EDA}]_{0}$ 


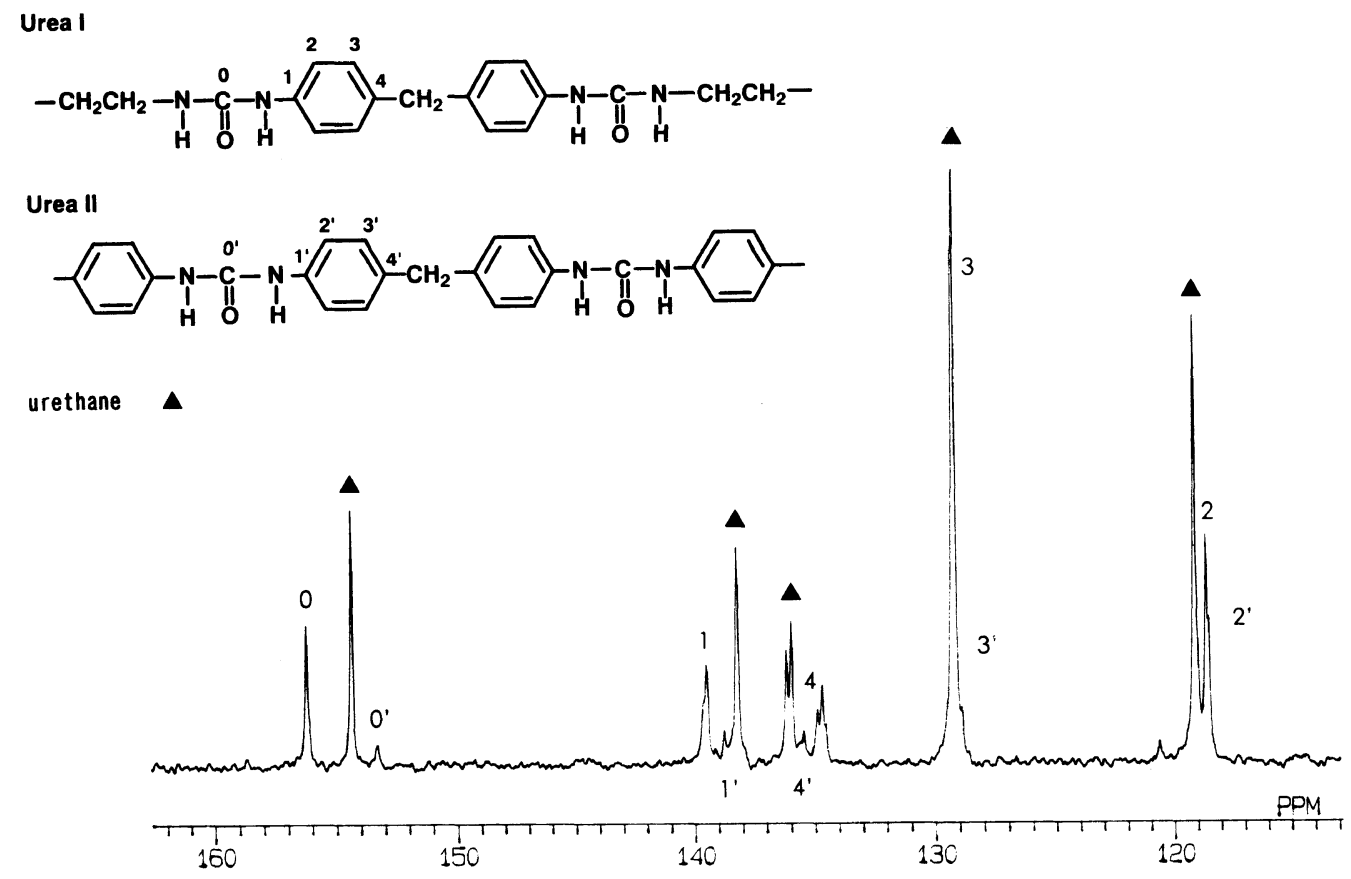

Figure 1. ${ }^{13} \mathrm{C}$ NMR spectrum of DSPUU2 ([Acetone $\left.]_{0} /[\mathrm{EDA}]_{0}=1.4\right)$.

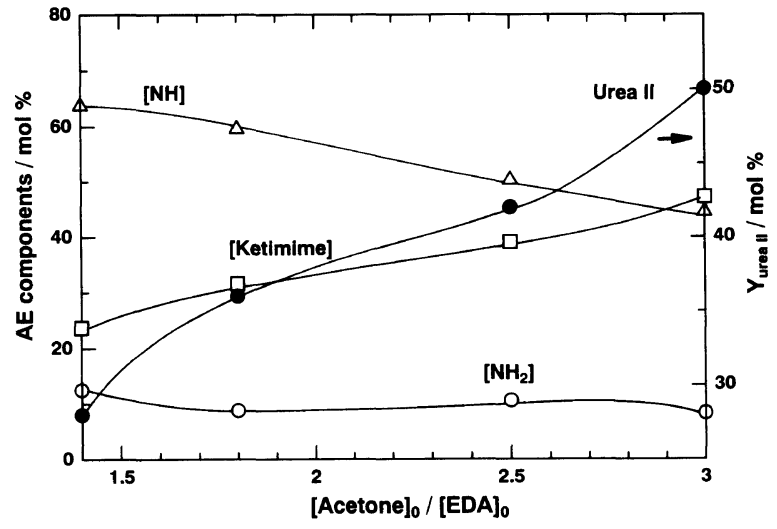

Figure 2. Plots of AE composition and Urea II yield $v s$. [Acetone $]_{0} /$ $[\mathrm{EDA}]_{0}$ for preparation of AE samples

as well as the yield of Urea II, $Y_{\text {Urea II }}\left(\fallingdotseq 100-Y_{\text {Urea I }}\right)$ calculated based on eq 2 . It is clearly pictured in this figure that with increasing $[\text { acetone }]_{0} /[\mathrm{EDA}]_{0}$, the $Y_{\text {Ureall }}$ gradually increases and the increase in this ratio corresponds to the increase in the concentrations of the ketimine groups of (1) ((2)) and water as described before. On the contrary, the decrease in the concentration of (3) accompanies with the increase in $Y_{\text {Ureall }}$. These indicate the positive correlation between the initial concentration of ketimine groups as well as water, and the $Y_{\text {Ureall }}$.

In the model DSPUU reaction ${ }^{9}$ we found that $\mathrm{N}$ isopropylidenebutylamine reacted with phenylisocyanate in the presence of water to form the mixture of $1-\left(N^{\prime}\right.$ phenylureido)butane and 1,3-diphenylurea (yield of the mixture on the basis of the NCO concentration; 97\%). The former compound corresponds to Urea I and the latter to Urea II in the case of DSPUU reactions. The reaction pathway forming the former compound, which is similar to that for the reaction of the Schiff base with phenylisocyanate $^{17}$ is that the intermediate compound was formed first from the addition reaction of the ketimine group with an NCO, then subjected to hydrolysis reaction by water forming 1-( $N^{\prime}$-phenylureido)butane (Scheme 3a). According to this reaction pathway the formation of 1,3-diphenylurea is unlikely. In addition $Y_{\text {Urea II }}$ for DSPUU2 reaction, for example, was calculated to be merely $3 \mathrm{~mol} \%$ based on the reaction rate constant $\left(5.1 \times 10^{-3} \mathrm{~kg} \mathrm{~mol}^{-1} \mathrm{~min}^{-1}\right)$ for ITPP-water reaction. ${ }^{18}$ Furthermore, an NCO-water reaction is generally catalyzed by the basic compounds, ${ }^{19}$ the reaction path for the Urea II formation is therefore the direct reaction of an NCO of ITPP with water catalyzed by the basic ketimine group.

We can not deny at this moment another possibility for the similar catalytic effect of the imidazolidine which may be a stronger base than the ketimine group even in the DSPUU reaction atmosphere. In fact the reaction of 2-pentamethylenoimidazolidine with phenylisocyanate in the presence of water also proceeded in the similar kind of pathways ${ }^{20}$ to those for the above ketiminephenylisocyanate reaction, giving the mixture of the same urea compounds ${ }^{9}$ (Scheme $3 b$ ). Hence we may reasonably deduce the catalytic effect of the imidazolidine, (3) (the imino group (NH)) as well. One may not consider the possibility for an amine catalyst because this group is consumed instantaneously by an NCO.

From the catalytic effect of the ketimine groups, the results shown in Figure 2 can be explained qualitatively; that is, the positive correlation between the initial concentration of the ketimine groups and $Y_{\text {UrealI }}$ for DSPUU2 - 5 reactions. The catalytic effect of the imidazolidine apparently seems to be weaker than that of the ketimine groups.

Based on the above results including those of DSPUU reaction model $^{9}$ Scheme 4 illustrates the elementary reactions in DSPUU reactions in the absence of acetic acid, that is, the reactions of ITPP (i) with the amino groups of EDA left unreacted in the reaction of acetone with EDA and with the amino groups of (1), (ii) with 


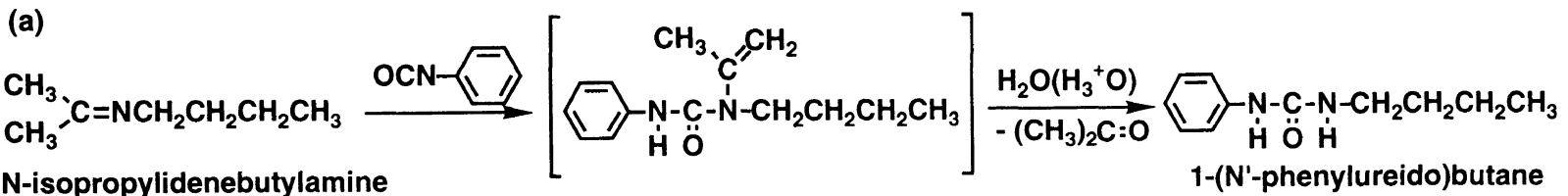

(b)

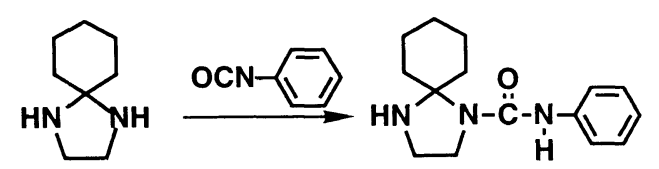

2-pentamethylenoimidazolidine

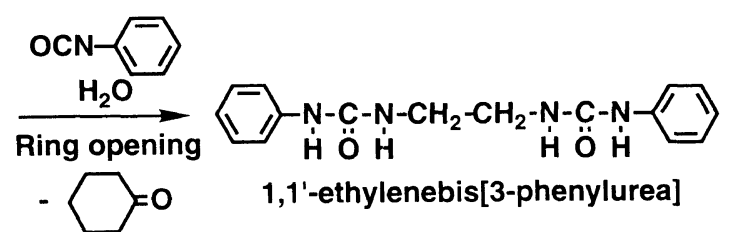

Scheme 3. (a) Reaction pathway to form 1-( $N^{\prime}$-phenylureido)butane from $N$-isopropylidenebutylamine and phenylisocyanate in the presence of water. (b) Reaction pathway to form 1,1'-ethylenebis[3-phenylurea] from 2-pentamethylenoimidazolidine and phenylisocyanate in the presence of water.

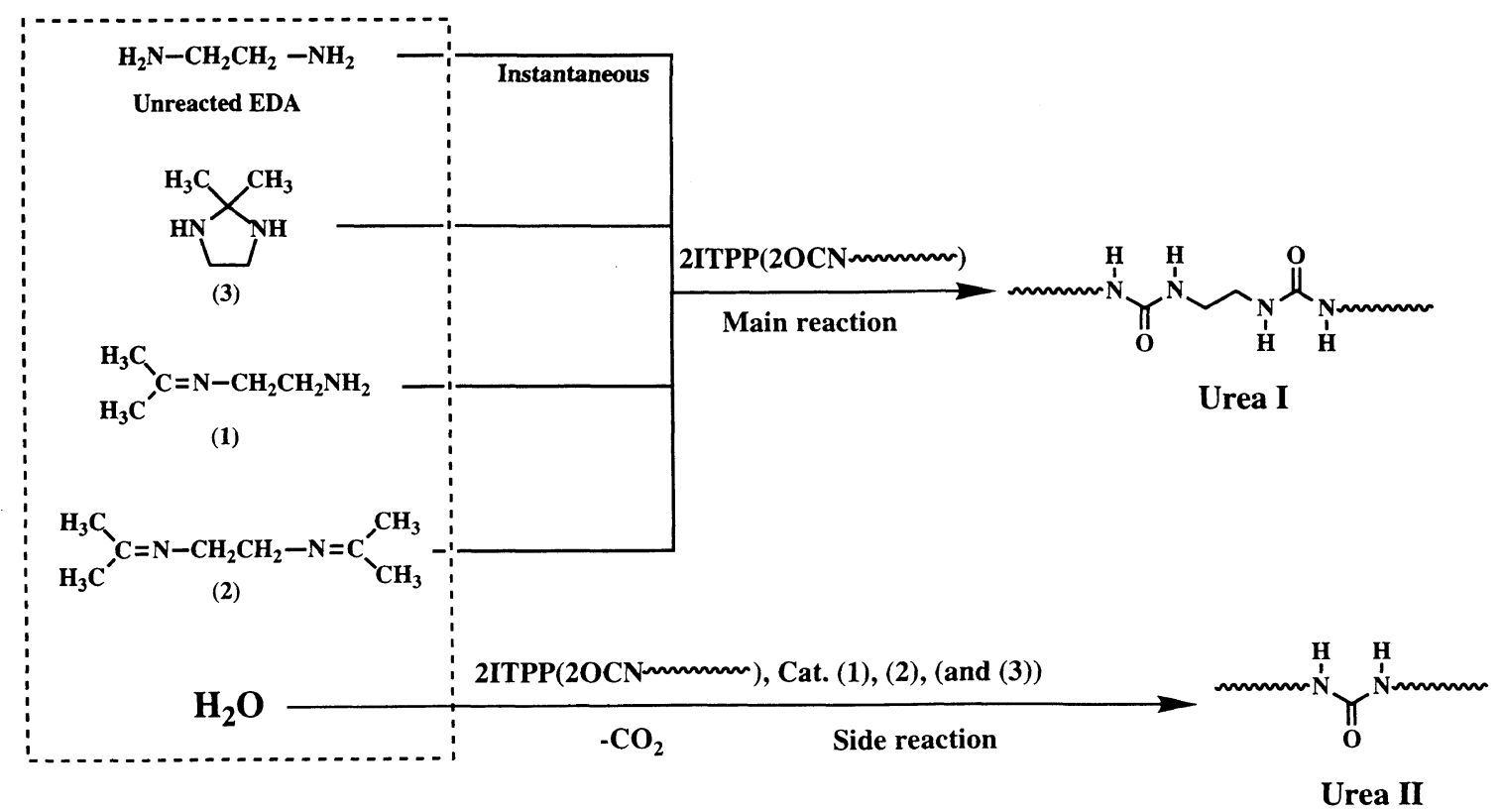

Scheme 4. Schematic representation of one of the reaction pathways ('direct' reactions) in the course of DSPUU reactions in the absence of an acid.

the ketimine groups of (1) and (2), (iii) with the imino groups of (3), and (iv) with water catalyzed by these ketimine and imino groups as the side reaction. In addition to the above 'direct' reactions with ITPP, another kind of possible reactions ought to be considered: that is, well-known 'demasking' reactions where (1) and (2) are capable of undergoing reformation reactions of the amino groups. ${ }^{5,6}$ The ring opening of (3) to form (1) by tautomeric relation between (3) and (1) ${ }^{9}$ is also included in this reaction category (Scheme 5). The regenerated amino groups are reacted with ITPP, consequently forming Urea I.

In the subsequent papers, for the purpose of knowing which of the above two kinds of reaction categories actually occur in the course of DSPUU reactions, mechanistic and kinetic studies will be done, relating to (i) the masking and demasking reaction of acetone with EDA, emphasizing on the latter which is particularly important in the case of DSPUU reactions, and to (ii) the direct reactions of ITPP with (1), (2), and (3).

Effect of Addition of Water to AE Samples on PUU Yield. In order for diminishing the base-catalyzed Urea
II formation reaction, the concentration of the ketimine groups of (1) and (2) (and minorly imino groups of (3)) should be reduced at the beginning or during the DSPUU reactions. We chose first as the adequate $\mathrm{AE}$ sample, the AE2 consisting of the lowest concentration of the ketimine groups among the AE samples prepared (Table I) and the upper limit concentration of EDA to avoid abrupt polymerization reaction.

Firstly an attempt was made to reduce the initial concentration of the ketimine groups by adding the significantly large amount of water to the AE2 sample for the preparation of AE6. As described before, the composition of the AE6 shifted to the slight increase in the concentrations of the imino and amino groups on the contrary, to the slight decrease in that of ketimine groups. Based only on this result it can be predicted that the resultant $Y_{\text {UrealI }}$ will be slightly decreased.

On the other hand, water is expected to accelerate the hydrolysis reaction rate of the ketimine groups, leading to concentration reduction of the groups during the reaction. Furthermore, from the quite different view point, water might also reduce $Y_{\text {Urea II }}$ indirectly by in- 


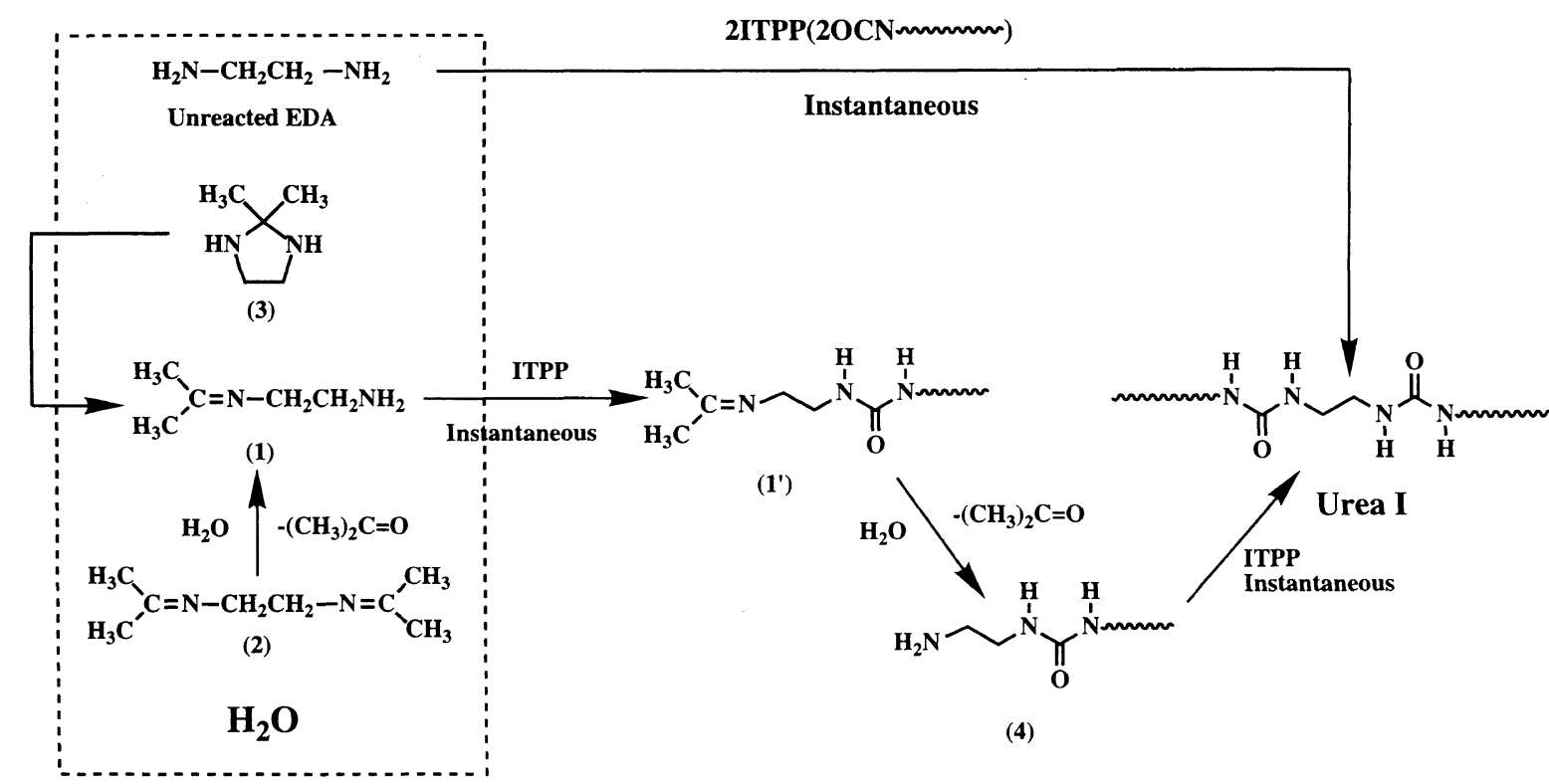

Scheme 5. Another kind of possible reaction pathways ('demasking' reactions) in DSPUU reactions in the absence of an acid.

creasing the rate of Urea I formation reaction resulting from the increased rate of the hydrolysis reaction of the intermediate (Scheme 3a) on the reaction pathway of the direct reaction of NCOs with the ketimine groups. ${ }^{9}$ The similar effect will also be expected for the direct reaction with (3) owing to the similarity of its reaction pathway to the above NCO-ketimine reaction. It should be noted, however, that Urea II will be reduced, provided that the rate of the addition reaction of ketimine groups (imino groups of (3)) with NCO groups is significantly larger than the hydrolysis reaction of the corresponding intermediates.

Table II lists $Y_{\text {Ureall }}$ for DSPUU6 reaction. The $Y_{\text {Urea II }}$ was increased, contrary to the above prediction. It may merely be due to the slight decrease in the ketimine concentration, while the significant increase in water concentration (see, Table I), giving more Urea II. From this experiment the important results were also obtained: (i) the hydrolysis rate of the ketimine groups was slow and (ii) the hydrolysis reactions of the intermediates formed on the pathways of the direct reactions of ITPP with the ketimine groups and with (3) contributed little to the decrease in $Y_{\text {Ureall}}$.

The similar DSPUU reaction (DSPUU7) was carried out by using AE7 sample. In this case, $Y_{\text {ureall }}$ was decreased due to the significant decrease in the concentration of the ketimine groups, agreeing with the previous discussion. However, considering the above two results the effect of water seems insufficient for the quantitative synthesis of PUUs.

\section{DSPUU Reactions in the Presence of Acetic Acid}

Therefore another attempt was made to accelerate the disappearance rate of the ketimine groups during the DSPUU reactions by referring the acid-catalyzed reaction of the hydrolysis reaction of the ketimine group in water. ${ }^{21}$ It should be noted here that although the acid is also capable of accelerating the formation reaction of the ketimine group, this reaction does not substantially take place since the amino groups formed from the ketimine group was consumed instantaneously by the

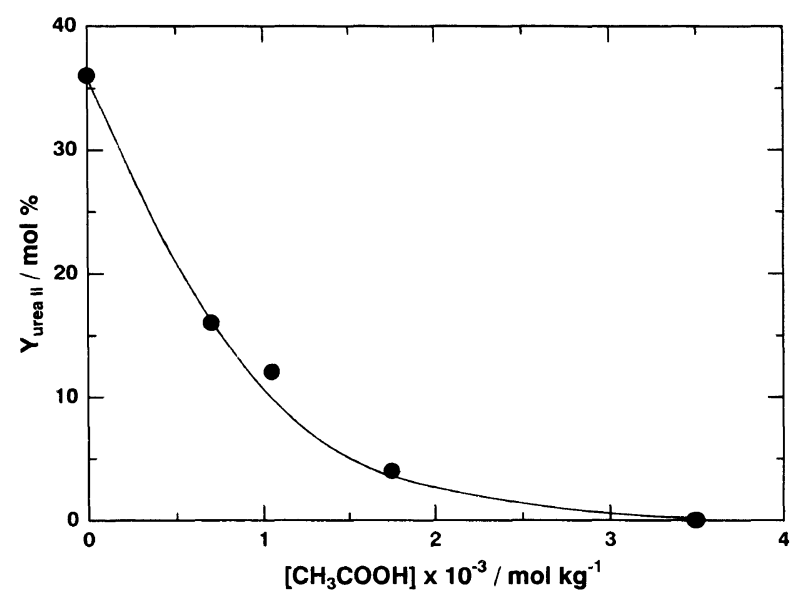

Figure 3. Acid concentration dependence of Urea II yield.

reaction with NCO groups. One may expect the acidcatalyzed direct reactions of $\mathrm{NCO}$ groups with the ketimine groups or the imino groups of (3). The nucleophilic reaction towards NCO is not substantially subject to acid catalysis ${ }^{19}$ in the acid concentration range investigated. The catalytic effect of the protonated amine may also be ruled out. Hence it is reasonable to think that the addition reactions of ITPP with the ketimine groups and with (3) are not catalyzed by the acid, while the hydrolysis reaction of these groups are subject to acid catalysis. Here, addition of acetic acid comes into effect, provided the previous condition with respect to the rate difference between the addition reaction and the hydrolysis reaction is satisfied (the former reaction rate should be significantly larger than the latter).

When we carried out the DSPUU reactions (DSPUU811) in the presence of acetic acid and water, it is surprisingly pictured in Figure 3 that the increase in the acid concentration lowered the Urea II concentration and approached zero $\left({ }^{13} \mathrm{C}\right.$ NMR spectrum is shown in Figure 4) at the acid concentration of $3.50 \times 10^{-3} \mathrm{~mol} \mathrm{~kg}^{-1}$. This tendency strongly indicates that $Y_{\text {UrealI }}$ depends on the rate of disappearance of the ketimine group (imino groups) owing to the acid-catalyzed hydrolysis reaction 

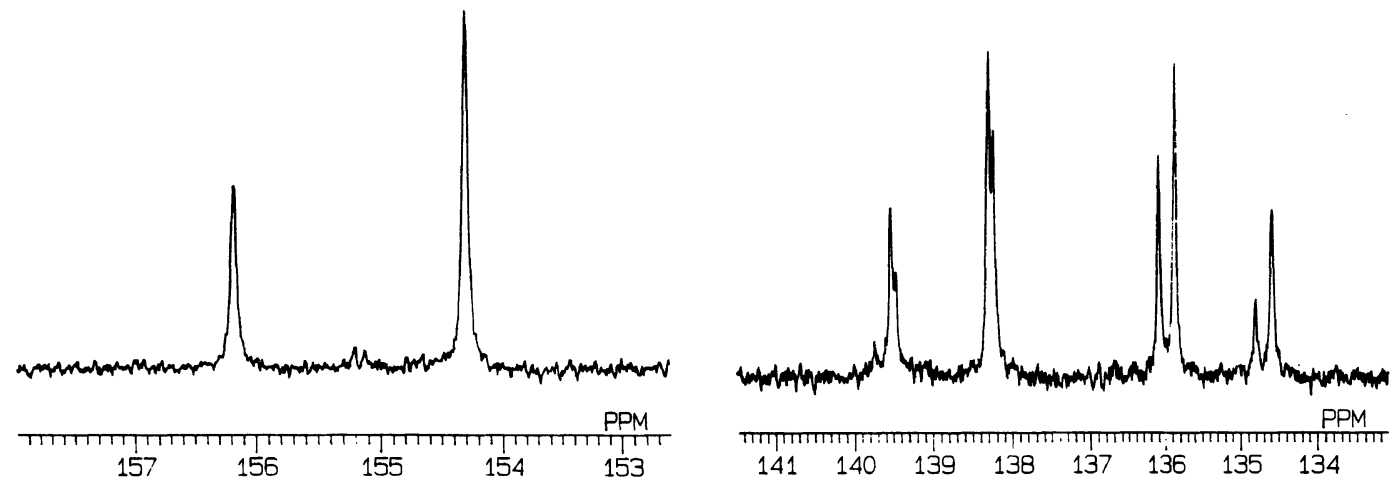

Figure 4. ${ }^{13} \mathrm{C}$ NMR spectrum of DSPUU11.

(reaction pathway $(2) \rightarrow(1) \rightarrow\left(1^{\prime}\right) \rightarrow(4)$ in Scheme 5). Alternatively it may be attributable to the acid-catalyzed hydrolysis reaction of the intermediate formed on the pathway of the direct reaction of NCO groups with the ketimine groups (Scheme $3 \mathrm{a}$ ). In the subsequent papers which of the above two kinds of the reaction pathways actually contributes to reduction in $Y_{\text {Urea II }}$ will be clarified.

Molecular Weight of DSPUU Polymer. The weightaverage molecular weight of the DSPUU10 sample $\left(\bar{M}_{w}\right)$ was as a representative $8.4 \times 10^{4} \mathrm{~g} \mathrm{~mol}^{-1}$ calculated by the eq 1 and approximately equal to that obtained by the conventional solution polymerization reaction using the ITPP with the same number-average molecular weight in DMAc under the condition that the concentration ratio of EDA to the ITPP was $1.10 .^{22}$ By titrating directly this conventional polymer (in $5 \mathrm{wt} \%$ DMAc solution) using a standardized $0.1 \mathrm{~N} \mathrm{HCl}$ chlorobenzene solution, the polymer contained $11.2 \mathrm{~mol} \%$ of the basic end groups based on the initial concentration of $\mathrm{NCO}$ groups of the ITPP, agreeing well with the theoretical concentration $(10.0 \mathrm{~mol} \%)$ of the amino groups, within the experimental error. On the other hand the end-group concentration of the DSPUU10 polymer was found to be $8.2 \mathrm{~mol} \%$, indicating that the ketimine groups and/or the imino groups may probably be left unreacted, depending on the rates of disappearance of the ketimine groups and the imidazolidine. Since identification of the end groups by ${ }^{1} \mathrm{H}$ and ${ }^{13} \mathrm{C}$ NMR failed due to its low concentration, an attempt to identify the end group will be made in one of the related papers by calculating the concentrations of above two groups which should theoretically be left unreacted at the polymer chain ends.
Acknowledgment. The authors are grateful to Dr. Kunihiko Okajima and Dr. Nobuchika Tamura, of Central Laboratory, Asahi Chemical Industry Co., Ltd., for their valuable comments and useful advices.

\section{REFERENCES}

1. G. Oertel, "Polyurethane Handbook," Hanser Publishers, 1985.

2. P. M. Knight and D. J. Lyman, Membrane Sci., 17, 245 (1984).

3. Dupont, U. S. Patent 2957852.

4. T. Matsui, Y. Arimatsu, and H. Suzaki, Sen-i Gakkaishi, 86, 46 (1993).

5. Z. W. Wicks, Jr., Progress in Organic Coatings, 3, 73 (1975).

6. R. R. Myers and J. S. Long, "Treatise on Coatings," Vol. 1, Part 1, Marcel Dekker, New York, 1967.

7. American Cyanamid Co., U. S. Patent 4528320.

8. Bayer, A. G., German Patent 2037458.

9. Y. Nakano, E. Yamazaki, H. Hanahata, K. Okajima, and Y. Kitahama, Bull. Chem. Soc. Jpn., 70, 1185 (1997).

10. S. Shiggia and J. G. Hanna, Anal. Chem., 20, 1084 (1948).

11. ASTM Method D 4274-83.

12. K. Kamide and H. Hanahata, Polym. Int., 31, 131 (1993).

13. K. Kamide, A. Kiguchi, and Y. Miyazaki, Polym. J., 18, 919 (1986).

14. A. Kaji and M. Murano, Polym. J., 22, 1065 (1990).

15. H. Hanahata and K. Kamide, Polym. Int., 38, 277 (1995).

16. E. Yamazaki and H. Hanahata, unpublished result.

17. K. Harada, Y. Mizoe, J. Furukawa, and S. Yamashita, Macromol. Chem., 132, 295 (1970).

18. H. Hanahata and J. Hiwatari, unpublished result

19. J. H. Saunders and K. C. Frisch, "Polyurethanes, Chemistry and Technology," Vol. 16, Part I, Krieger Publishing Company, 1983.

20. S. Witek, A. Bielawska, and J. Bielawski, Heterocyclics, 14, 1313 (1980).

21. W. P. Jencks, J. Am. Chem. Soc., 81, 475 (1959).

22. Preparation procedure was followed by ref 15 